\title{
High-temporal resolution fluvial sediment source fingerprinting with uncertainty: a Bayesian approach
}

\author{
Richard J. Cooper, ${ }^{1 *}$ Tobias Krueger, $^{2}$ Kevin M. Hiscock $^{1}$ and Barry G. Rawlins ${ }^{3}$ \\ ${ }^{1}$ School of Environmental Sciences, University of East Anglia, Norwich, UK \\ 2 IRI THESys, Humboldt University, Berlin, Germany \\ ${ }^{3}$ British Geological Survey, Keyworth, Nottingham, UK
}

*Correspondence to: Richard J. Cooper, School of Environmental Sciences, University of East Anglia, Norwich Research Park, Norwich, NR4 7TJ, UK. E-mail: Richard.J.Cooper@uea.ac.uk

This is an open access article under the terms of the Creative Commons Attribution License, which permits use, distribution and reproduction in any medium, provided the original work is properly cited.

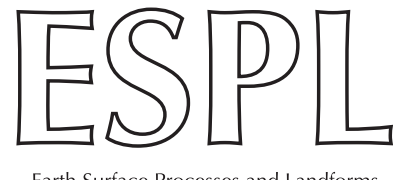

ABSTRACT: This contribution addresses two developing areas of sediment fingerprinting research. Specifically, how to improve the temporal resolution of source apportionment estimates whilst minimizing analytical costs and, secondly, how to consistently quantify all perceived uncertainties associated with the sediment mixing model procedure. This first matter is tackled by using direct X-ray fluorescence spectroscopy (XRFS) and diffuse reflectance infrared Fourier transform spectroscopy (DRIFTS) analyses of suspended particulate matter (SPM) covered filter papers in conjunction with automatic water samplers. This method enables SPM geochemistry to be quickly, accurately, inexpensively and non-destructively monitored at high-temporal resolution throughout the progression of numerous precipitation events. We then employed a Bayesian mixing model procedure to provide full characterization of spatial geochemical variability, instrument precision and residual error to yield a realistic and coherent assessment of the uncertainties associated with source apportionment estimates. Applying these methods to SPM data from the River Wensum catchment, UK, we have been able to apportion, with uncertainty, sediment contributions from eroding arable topsoils, damaged road verges and combined subsurface channel bank and agricultural field drain sources at 60- and 120-minute resolution for the duration of five precipitation events. The results presented here demonstrate how combining Bayesian mixing models with the direct spectroscopic analysis of SPM-covered filter papers can produce high-temporal resolution source apportionment estimates that can assist with the appropriate targeting of sediment pollution mitigation measures at a catchment level. (c) 2015 The Authors. Earth Surface Processes and Landforms published by John Wiley \& Sons Ltd.

KEYWORDS: fingerprinting; Bayesian mixing model; uncertainty; X-ray fluorescence; filter papers

\section{Introduction}

Fluvial systems affected by elevated sediment volumes experience an array of detrimental impacts which threaten sustainable ecosystem functioning. Fine clay and silt sized fractions increase turbidity, clog fish gills, smother gravel salmonid spawning grounds and benthic habitats, reduce oxygen circulation through the streambed, and abrasively scour macrophytes, periphyton and small invertebrates (Acornley and Sear, 1999; Hilton et al., 2006; Bilotta and Brazier, 2008). The high specific surface area of fine grained material $(<63 \mu \mathrm{m}$ diameter) also enables suspended particulate matter (SPM) to act as a major vector for the transport of phosphorus and other potentially toxic pollutants through stream systems that can lead to eutrophication and fish kills (House et al., 1995; Smith et al., 1999; Evans et al., 2004). Alongside ecological concerns there is an economic impact, with high rates of sedimentation reducing navigability, enhancing flood risk, and increasing dredging and water treatment costs (Pretty et al., 2003; Hilton et al., 2006; Owens et al., 2010). Under national and international legislation, such as the US Clean Water
Act (1972) and the European Union (EU) Water Framework Directive (2000/60/EC), water bodies are expected to achieve good ecological and chemical status, something many fluvial systems in Europe are at risk of failing due to excessively high sediment ingress from the eroding terrestrial environment (e.g. Environment Agency, 2009). Mitigation measures are therefore required to reduce the amount of land-to-river sediment transfer, but for these to be targeted effectively, it is essential to first understand the provenance of the sediment within the catchment.

Sediment source apportionment research has become increasingly common over recent years as a method for estimating the sediment contribution from various eroding terrestrial sources to fluvial sediment load via a mixing model approach. A variety of so called 'fingerprints' have been used to help differentiate potential sediment source areas, including major and trace elements (Walling et al., 2008; Evrard et al., 2011; Navratil et al., 2012), colour coefficients (Martínez-Carreras et al., 2010a), fallout radionuclides (Huisman and Karthikeyan, 2012; Olley et al., 2013; Smith et al., 2013; Theuring et al., 2013), mineral magnetism (Russell et al., 2001), organic and inorganic carbon 
(Schindler Wildhaber et al., 2012; Slimane et al., 2013), and compound specific stable isotopes (Blake et al., 2012; Hancock and Revill, 2013). Earlier traditional fingerprinting studies estimated sediment source contributions by optimizing mixing model parameters using simply the means or medians of the input data constellations (e.g. Collins et al., 1997; Gruszowski et al., 2003). This approach was of limited use as the omission of measurement error, source variability and residual model error meant that the mixing model did not provide any measure of the uncertainties surrounding the 'optimal' source contribution. This shortcoming motivated more recent studies to couple the parameter optimization with Monte-Carlo based stochastic sampling of input/output data constellations which reflect information on source and target sediment variability available through repeat measurements (e.g. Motha et al., 2003; Collins et al., 2013a; Wilkinson et al., 2013). However, this approach can still be considered somewhat inconsistent since two different error assumptions are used (one for the Monte-Carlo simulation and one for the likelihood function to be maximized) thus making interpretation of uncertainties unrealistic. An alternative, consistent and flexible framework for dealing with all perceived uncertainties in sediment mixing models is available through Bayesian statistics (e.g. Fox and Papanicolaou, 2008; Palmer and Douglas, 2008; Rowan et al., 2011; D'Haen et al., 2012; Massoudieh et al., 2012; Dutton et al., 2013). These Bayesian approaches are advantageous over traditional optimization methods as they allow all known and residual uncertainties associated with the mixing model and the dataset to be coherently translated into parameter probability distributions. However, to date there remain methodological differences within the Bayesian framework between previous studies which suggests research should now centre on the choice of appropriate error models. Contributing to this field is one aim of this paper.

Another focus of current research is high-temporal resolution source apportionment, whereby the contribution from various sources within a catchment can be estimated throughout the duration of numerous precipitation events across the hydrological year (Legout et al., 2013). To date such studies have been rare because the required high-temporal resolution information is often too expensive and time consuming to collate (Walling, 2013), but it is essential if one is to understand catchment processes sufficiently well to enable erosion mitigation measures to be targeted effectively. Recent progress has been made in this area with the development of spectroscopy as a rapid, accurate and inexpensive technique to analytically determine fingerprint properties using relatively small volumes of sediment (e.g. Poulenard et al., 2009, 2012; Martínez-Carreras et al., 2010b; Evrard et al., 2013). In this study, this area of research has been developed further by utilizing the methodology of Cooper et al. (2014), whereby the geochemistry of SPM is analysed by X-ray fluorescence spectroscopy (XRFS) and diffuse reflective infrared Fourier transform spectroscopy (DRIFTS) directly from sediment-covered filter papers. Combining this with automatic water samplers, large numbers of SPM samples have been quickly, accurately and inexpensively analysed to generate high-temporal resolution geochemical time series for the duration of numerous precipitation events in the River Wensum catchment, UK. These data have then been analysed with a Bayesian mixing model to yield hightemporal resolution fluvial sediment source apportionment estimates that fully characterize both instrument error and environmental variability in measured sediment geochemistry.

\section{Methods}

\section{Monitoring location}

The River Wensum is a $78 \mathrm{~km}$ long, enriched, lowland calcareous river in eastern England, with Site of Special Scientific
Interest (SSSI) and European Special Area of Conservation (SAC) status. However, $99.4 \%$ of its protected habitat is in an unfavourable and declining state due, primarily, to excessive sediment and nutrient loadings (Sear et al., 2006), thereby making it an ideal location for developing an improved sediment source apportionment technique. The Wensum drains an area of $593 \mathrm{~km}^{2}$ which is divided into 20 sub-catchments. One of these, the $20 \mathrm{~km}^{2}$ lowland Blackwater sub-catchment, represents the area intensively monitored as part of the River Wensum Demonstration Test Catchment (DTC) project (Wensum Alliance, 2014). The DTC project aims to evaluate the extent to which on-farm mitigation measures can costeffectively reduce the impacts of diffuse water pollution on river ecology while still maintaining food production capacity. The Blackwater sub-catchment (Figure 1) is in turn divided into six 'mini-catchments' A to $F$, each of which has a bankside kiosk at its outlet monitoring parameters including $\mathrm{pH}$, turbidity, temperature, stage, flow, ammonium, chlorophyll, dissolved oxygen and electrical conductivity at 30-minute resolution. Two kiosks ( $\mathrm{E}$ and $\mathrm{F}$ ) additionally measure nitrate, and reactive and total phosphorus. Each kiosk, including a seventh kiosk at site $M$ nested within mini-catchment $A$, also encompass an ISCO automatic water sampler (Teledyne ISCO, Lincoln, NE) containing 24, 1 I polypropylene sample bottles.

Mini-catchment A $\left(52^{\circ} 47^{\prime} 14^{\prime \prime} \mathrm{N}, 1^{\circ} 07^{\prime} 42^{\prime \prime} \mathrm{E}\right)$, the focus area for this research, is $\sim 40 \mathrm{~m}$ above sea level and covers an area of $5.4 \mathrm{~km}^{2}$ with a gentle slope of $\sim 0.37^{\circ}$. Intensively farmed arable land constitutes $92 \%$ of this headwater catchment (with wheat, barley, sugar beet, oilseed rape and spring beans in rotation), with $5 \%$ grassland, $2 \%$ woodland, and $1 \%$ urban areas. The bedrock of mini-catchment A is Cretaceous White Chalk at a depth of $\sim 20 \mathrm{~m}$. Overlaying the chalk are superficial deposits of Mid-Pleistocene diamicton glacial tills, principally chalky, flint-rich boulder clays of the Sheringham Cliffs $(0.2-0.5 \mathrm{~m}$ depth) and Lowestoft Formations (0.5-20 m depth), interspersed with layers of glaciofluvial and glaciolacustrine sands and gravels. These in turn are overlain by a Late Pleistocene silty loess deposit (coverloam) and Holoceneage alluvium and river terrace deposits. The principal soil types are clay loam to sandy clay loam soils to a depth of at least 0.2 m (Hiscock, 1993; Hiscock et al., 1996; Lewis, 2011; Rawlins, 2011).

The Wensum catchment has a temperate maritime climate with a 1981-2010 mean annual temperature of $10.1{ }^{\circ} \mathrm{C}$ and mean annual precipitation total of $674 \mathrm{~mm}$. Over the same period, mean monthly precipitation totals were highest during October $(68.2 \mathrm{~mm})$ and lowest during February $(41.7 \mathrm{~mm})$ (Meteorological Office, 2013). During the October 2011-September 2013 DTC monitoring period, average annual temperatures were $9 \%$ lower $\left(9.2{ }^{\circ} \mathrm{C}\right)$ than the $1981-$ 2010 mean, with average annual rainfall totals $8 \%$ higher (729 mm).

\section{Source area sampling}

Prior to conducting the field sampling campaign, catchment walk over surveys were carried out under both wet and dry conditions to identify potential sediment-contributing areas to the River Blackwater. Stream channel banks, agricultural field drains, damaged road verges and arable topsoils were identified as the four main sediment source areas within minicatchment A. Whilst it was not possible to completely rule out sediment contributions from other sources, such as woodland, grassland, or windblown dust, our observations suggested any such inputs were negligible. 


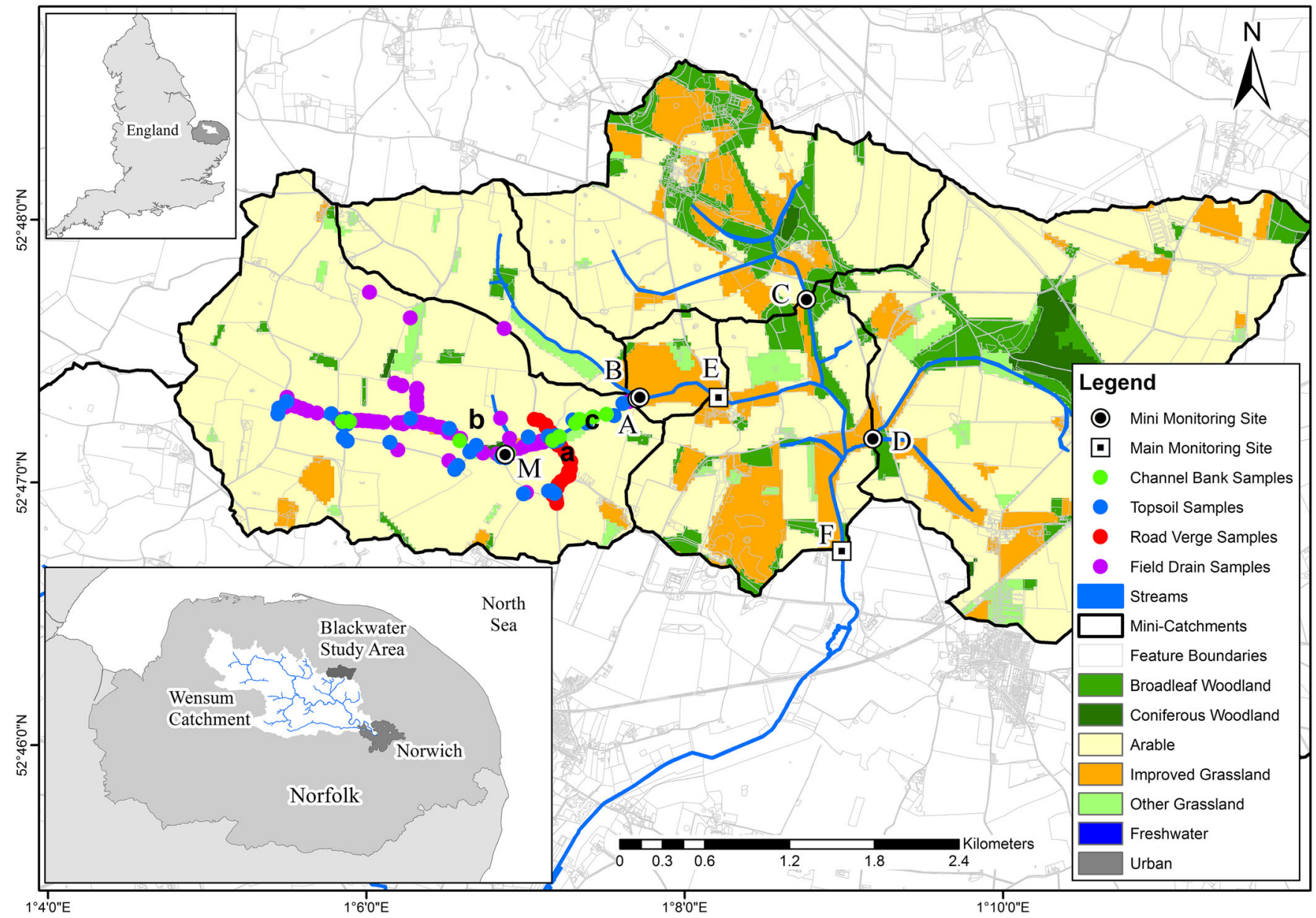

Figure 1. The Blackwater sub-catchment of the River Wensum, Norfolk, showing the land cover of mini-catchments A-F and the locations of surface and subsurface sediment source sampling. Lower case letters $(\mathrm{a}, \mathrm{b}, \mathrm{c})$ refer to the locations of the photographs in Figure 2 . This figure is available in colour online at wileyonlinelibrary.com/journal/espl

\section{Surface sources}

For both topsoils and road verges, 30 samples were collected from each source as $<50 \mathrm{~mm}$ depth surface scrapes from areas susceptible to erosion with potential connectivity to the stream channel. This primarily meant sampling field entrances, tramlines and narrow road sections where soil surfaces become damaged by heavy vehicular use and act as critical source areas for sediment ingress into the river. In particular, samples were collected from areas in close proximity to metalled roads as these had been observed to increase field-to-river connectivity by channelling sediment-laden water during precipitation events (Figure 2a). Differences in the geochemistry between topsoil and road verge material likely reflect two factors: soil management and sediment deposition. Arable topsoil (Figure 2b) geochemistry will have been modified by intensive cultivation, crop residues and frequent applications of organic and inorganic fertilizers. Conversely, uncultivated road verges will have experienced enhanced deposition of material from vehicles and salt inputs from winter road gritting. To ensure actual road verge material was sampled and not transient sediments from other sources deposited on the road during prior precipitation events, the outermost layer of verge sediment was brushed away to expose fresh material for sampling.

\section{Channel banks}

Due to the Blackwater catchment being an intensive arable landscape, stream channels have been extensively straightened and deepened to reduce water residence times (Figure 2c). This has resulted in the complete disconnection of the river from its floodplain, with channel banks typically rising $>2 \mathrm{~m}$ above the bed at an angle of $\sim 20^{\circ}$ to $30^{\circ}$ to form deep V-shaped channels. At 10 locations along the $2.9 \mathrm{~km}$ stream reach in minicatchment A, channel bank material was collected as surface scrapes at depths of 10,30 and $50 \mathrm{~cm}$ above the streambed, such that 30 samples were collected in total. The position 0-50 cm above the bed represents the zone most actively eroded by the stream (with stage lower than $50 \mathrm{~cm}$ for $95 \%$ of the monitoring period) and is located within the chalky boulder clay deposits of the Lowestoft Formation. Above $50 \mathrm{~cm}$, banks become densely vegetated with grasses and ground elder (Aegopodium podagraria), stabilizing the upper sections. Upper banks were therefore not considered to be a major sediment source, likely only becoming important during episodes of periodic slumping or channel dredging operations, of which none were observed during the study period.

\section{Field drains}

Most of the Blackwater catchment is extensively under-drained by a dense network of agricultural field drains installed during numerous phases of land drainage works over the past 60-70 years. Over 120 drains were identified discharging directly into the stream at depths of 100 to $155 \mathrm{~cm}$ below ground level. The discharge from each drain varies considerably depending on the season, antecedent weather conditions, soil moisture and the catchment area drained by the individual pipes, with the fastest recorded flows exceeding $1.0 \mathrm{I} \mathrm{s}^{-1}$. Grab samples taken from each flowing drain were collected over several months and bulked together (necessary due to typically low sediment concentrations of $<2 \mathrm{mg} \mathrm{I}^{-1}$ during sampling periods) to yield 30 sediment samples for analysis. 


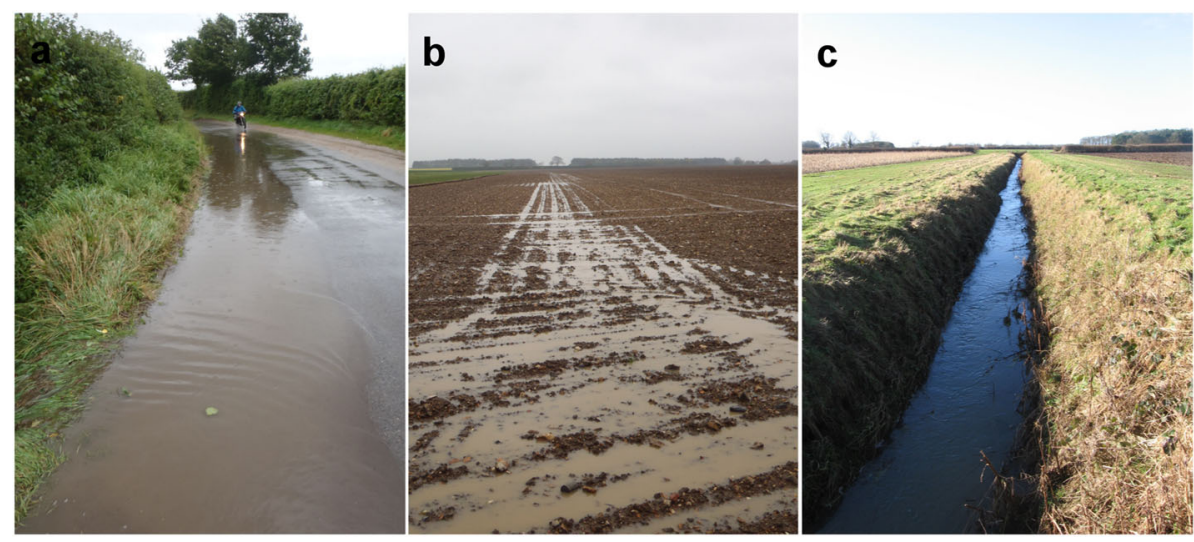

Figure 2. Images of the Blackwater catchment. (a) Metalled roads increase field-to-river connectivity by channelling sediment-laden surface runoff into roadside ditches that discharge directly into the river. (b) Erosion of exposed arable topsoils during a heavy precipitation event. (c) A straightened and deepened channel profile typical of this region. The top of the channel is $c .4 \mathrm{~m}$ wide. This figure is available in colour online at wileyonlinelibrary.com/journal/espl

\section{SPM sampling}

The bankside ISCO automatic sampler at the outlet to minicatchment A was remotely activated to collect 1 I stream water grab samples every 60- or 120-minutes for the duration of 11 moderate-to-heavy precipitation events $(>8 \mathrm{~mm}$ rainfall total per event) that occurred between September 2012 and October 2013. Results for five of these events (5 October 2012, 24, 26, 27 November 2012 and 14 February 2013) are presented here, selected because they encompassed a range of low, medium and high flow conditions. The principal advantage of using ISCO automatic samplers as opposed to the time-integrated samplers commonly employed in sediment fingerprinting studies (Phillips et al., 2000), is the increased temporal resolution, and thereby understanding of catchment processes, that can be achieved by sampling at regular short intervals. Stage was recorded every 30 minutes by a pressure transducer, whilst precipitation was recorded at 15-minute intervals via a tippingbucking rain gauge.

\section{Laboratory analysis}

All stream water samples were returned to the laboratory and vacuum filtered through Millipore quartz fibre filter (QFF) papers (Merck Millipore, Billerica, MA, USA) to extract particulate matter. These filters have a particle retention rating of $99.3 \%$ at $0.45 \mu \mathrm{m}$ and $99.1 \%$ at $0.7 \mu \mathrm{m}$ (Cooper et al., 2014). The SPMcovered filters were subsequently oven dried at $105{ }^{\circ} \mathrm{C}$ for two hours before being weighed to determine sediment mass retention. A Beckman Coulter LS13320 Laser Diffraction Particle Size Analyser (Beckman Coulter, CA, USA) was used to determine the grain size distribution of both SPM and source area sediments following the addition of Calgon and two minutes sonication $(18 \mathrm{~W})$ to disperse re-aggregated flocs. Analysis of 15 stream water samples revealed an average median $\left(d_{50}\right)$ particle size by volume of $8.94 \pm 5.03 \mu \mathrm{m}$ for SPM. To ensure the more consolidated source area materials had particle size distributions, and thus geochemistry (Horowitz, 1991), comparable to fluvial SPM, each sample was mixed with Milli-Q water (18.2 M $\Omega . c m$; Merck Millipore, Billerica, MA, USA) and placed in a sonic bath for seven minutes to disaggregate clasts. The material was then wet sieved to sub-63 $\mu \mathrm{m}$ and 25 mg were transferred on to QFF papers by vacuum filtration before oven drying for two hours. Once sieved down to sub-63 $\mu \mathrm{m}$, the $d_{50}$ particle size of bulked topsoil, road verge and field drain material was comparable to that of SPM (Table I), although a Student's $t$-test revealed channel bank $d_{50}$ values remained significantly different $(p=0.002)$ from SPM.

The geochemistry of all sediment-covered filter papers was analysed directly by XRFS and DRIFTS, using the methods described in detail by Cooper et al. (2014). Spectroscopic analysis of filter papers has many advantages over other analysis techniques commonly employed in fingerprinting studies, such as inductively coupled plasma (ICP), colorimetry, acid-digestion and loss-on-ignition. The principal benefits being that large numbers of samples can be quickly and cheaply analysed, non-destructively, from small sediment masses (only $5 \mathrm{mg}$ of

Table I. Geochemistry and median particle sizes for the $63 \mu \mathrm{m}$ sieved source area sediments and suspended particulate matter (SPM) from the five selected precipitation events

\begin{tabular}{|c|c|c|c|c|c|c|c|c|c|c|c|c|c|c|}
\hline \multirow[b]{2}{*}{ Source areas } & \multirow[b]{2}{*}{ Statistic } & \multicolumn{12}{|c|}{ Concentrations (weight \%) } & \multirow{2}{*}{$\begin{array}{l}d_{50} \\
(\mu \mathrm{m})\end{array}$} \\
\hline & & $\mathrm{Al}$ & $\mathrm{Ca}$ & $\mathrm{Ce}$ & $\mathrm{Fe}$ & K & $\mathrm{Mg}$ & $\mathrm{Mn}$ & $\mathrm{Na}$ & $P$ & $\mathrm{Si}$ & $\mathrm{Ti}$ & OC & \\
\hline \multirow[t]{2}{*}{$\operatorname{SPM}(n=86)$} & Mean & 9.09 & 16.88 & 0.0059 & 7.17 & 1.56 & 0.72 & 0.09 & 0.25 & 0.25 & 8.23 & 0.48 & 12.20 & 8.94 \\
\hline & SD & 1.57 & 4.96 & 0.0010 & 0.72 & 0.21 & 0.11 & 0.02 & 0.03 & 0.05 & 4.04 & 0.06 & 2.60 & 5.03 \\
\hline \multirow[t]{2}{*}{ Channel banks $(n=30)$} & Mean & 6.97 & 35.47 & 0.0036 & 5.04 & 1.19 & 0.61 & 0.01 & 0.19 & 0.07 & 5.40 & 0.45 & 0.92 & 4.07 \\
\hline & $\mathrm{SD}$ & 2.34 & 7.65 & 0.0013 & 1.65 & 0.44 & 0.18 & 0.02 & 0.06 & 0.03 & 4.80 & 0.09 & 2.16 & 2.27 \\
\hline \multirow[t]{2}{*}{ Field drains $(n=30)$} & Mean & 6.89 & 17.50 & 0.0049 & 8.21 & 1.12 & 0.51 & 0.22 & 0.26 & 0.28 & 9.95 & 0.38 & 9.24 & 8.43 \\
\hline & SD & 2.49 & 8.23 & 0.0015 & 5.14 & 0.39 & 0.17 & 0.29 & 0.09 & 0.19 & 9.50 & 0.11 & 4.89 & 1.34 \\
\hline \multirow[t]{2}{*}{ Road verges $(n=30)$} & Mean & 10.40 & 6.63 & 0.0086 & 6.12 & 2.08 & 1.01 & 0.15 & 0.48 & 0.33 & 18.09 & 0.61 & 12.85 & 9.37 \\
\hline & SD & 0.99 & 1.32 & 0.0007 & 0.48 & 0.11 & 0.09 & 0.02 & 0.05 & 0.04 & 2.34 & 0.02 & 1.19 & 0.62 \\
\hline \multirow[t]{2}{*}{ Topsoils $(n=30)$} & Mean & 14.07 & 3.97 & 0.0091 & 6.93 & 2.45 & 0.88 & 0.11 & 0.41 & 0.28 & 18.73 & 0.66 & 10.97 & 7.34 \\
\hline & SD & 1.17 & 2.00 & 0.0008 & 0.62 & 0.23 & 0.07 & 0.01 & 0.04 & 0.06 & 2.11 & 0.02 & 1.82 & 1.14 \\
\hline
\end{tabular}


material required) to yield a wide array of geochemical and mineralogical data with a high degree of accuracy. This makes such spectroscopic analysis conducive to high-temporal resolution monitoring programmes such as the one presented here. Concentrations of 11 major elemental fingerprints ( $\mathrm{Al}, \mathrm{Ca}, \mathrm{Ce}$, $\mathrm{Fe}, \mathrm{K}, \mathrm{Mg}, \mathrm{Mn}, \mathrm{Na}, \mathrm{P}, \mathrm{Si}, \mathrm{Ti}$ ) were determined (Table I), alongside additional estimates for organic carbon (OC).

\section{Discriminating source areas}

Before including any fingerprints in the model, the mixing space geometry of source area geochemistry was examined via a principal components analysis. The non-parametric Kruskal-Wallis $\mathrm{H}$-test was then applied to identify which of the elements were significantly different between at least two source areas and thereby able to discriminate between them. A stepwise linear discriminant analysis variable selection procedure based on the minimization of the Wilk's Lambda criterion with leave-one-out cross validation was also employed to quantitatively determine the proportion of source area samples that could be correctly classified (Collins et al., 1997). Prior to this statistical discrimination, silicon (Si) and manganese (Mn) were removed as potential fingerprints due to the lower precision of XRFS estimates compared with other elements (Cooper et al., 2014). Organic carbon and phosphorus (P) were also excluded due to these being generated within the stream environment via phytoplankton and macrophyte production (autochthonous), thereby rendering these non-conservative tracers. With the remaining eight elements there was an implicit assumption of conservative transport from source areas to the stream channel. Considering that SPM geochemistry fell within the range of the four source areas (Table I), and given this analysis focuses solely on major elements as opposed to isotopes where there is greater opportunity for fractionation (Matsumoto et al., 2007), we regard this assumption to be valid within the residual error range considered in the mixing model (see later).

\section{Bayesian mixing model}

The source apportionment model was programmed in the open source software JAGS version 3.3.0 (Just Another Gibbs Sampler; Plummer, 2003) within the R environment (R Development Core Team, 2013). JAGS performs hierarchical Bayesian inference using a Gibbs sampling Markov chain Monte-Carlo (MCMC) algorithm on (multivariate) prior parameter distributions and a likelihood function to estimate the posterior parameter distributions. This Bayesian approach, where the parameters are treated as random variables, is advantageous over traditional maximum likelihood optimization methods as it enables all known and residual uncertainties associated with the dataset to be coherently incorporated into the posterior distributions. The mixing model setup employed here represents a modified version of the empirical Bayes stable isotope model developed by Parnell et al. (2013), and is succinctly summarized by the Directed Acyclic Graph (DAG) in Figure 3 which links together sets of random variables with their associated conditional dependencies. Symbol meanings are as follows: $Y$ and $S$ are the concentrations of fingerprints in SPM and source area sediments, respectively; $P$ and $\Phi$ are the sediment contributions of each source area in original and isometric log-ratio (ILR)-transformed space (see later); $j$ and $k$ are the fingerprint and source indices; $\sum$ are covariance matrices; $\sigma^{2}$ are variances; $\mu$ are means; $i$ the model timestep index; and MVN, N, Inv-W and Inv- $\Gamma$ represent multivariate normal,

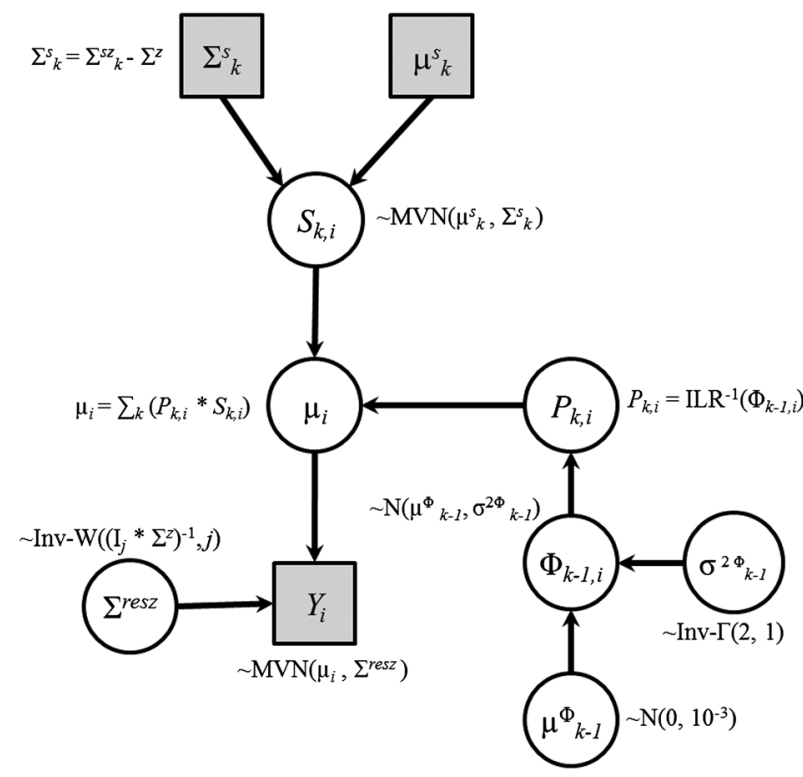

Figure 3. A Directed Acyclic Graph (DAG) of the Bayesian mixing model used for sediment source apportionment. Grey squares indicate nodes for observed data, whilst white circles indicate random variables estimated by the MCMC procedure. Respective prior distributions and deterministic link equations are noted alongside.

normal, inverse multivariate Wishart and inverse gamma distributions, respectively.

The general model formula is essentially a mass balance, whereby the concentration of each fingerprint property in SPM $(Y)$ is derived from the concentration of that fingerprint in each source area $(S)$ multiplied by the proportional sediment contribution from that source $(P)$. For each model time-step, data are drawn from new source composition distributions, albeit with the same prior, thereby incorporating temporal variability in sediment source geochemistry into the model. Whilst we approximate $\mu_{k}^{s}$ and $\sum_{k}^{s}$ empirically from the repeat source samples, other studies have employed a full Bayesian approach (e.g. Fox and Papanicolaou, 2008) in which all input nodes are stochastic and typically assigned uninformative prior hyper-parameters distributions. This relaxes the assumption that the repeat source samples are fully characteristic of the source variability across the catchment (Fox and Papanicolaou, 2008). However, due to numerical difficulties in ensuring all covariance matrices meet positive-definiteness criteria, we used the empirical $\mu_{k}^{s}$ and $\sum_{k}^{s}$ to specify the multivariate normal distributions of $S$. Previous investigations by Parnell et al. (2013) revealed no significant difference in posterior distributions between their empirical Bayes model and a fully Bayesian treatment. The resulting dimension reduction also has the added advantage that model convergence occurs much faster than for a full Bayesian approach (Massoudieh et al., 2012).

For the prior probability on the proportions $(P)$ we followed the procedure of Parnell et al. (2013) and applied a geometric transformation to the data. In this instance the isometric logratio (ILR) was used (Egozcue et al., 2003), although additive and centred log-ratio transformations are also possible (e.g. Semmens et al., 2009; Hopkins and Ferguson, 2012). The advantage of transforming the data is that proportions are independent in transformed space on the complete real scale, thus allowing univariate normal priors, while all proportions are positive and sum to unity in the original space. The ILR backtransformation $\left(\mathrm{ILR}^{-1}\right)$ takes values of $\Phi$ and returns real $P$ values by re-normalizing with the $k-1 \times k$ triangular Helmert matrix (Egozcue et al., 2003). The $\Phi$ values themselves are 
estimated from semi-informative prior hyper-parameter distributions of $\mu^{\Phi}$ and $\sigma^{2, \Phi}$.

Combined instrument and residual error $\left(\sum^{\text {resz }}\right)$ was incorporated into the model via a semi-informative, multivariate, inverse-Wishart prior distribution. This residual error term is important because it incorporates all model uncertainties which have not been specified explicitly. Here, the inverse of the Wishart scale matrix is parameterized by the summation of an identity matrix $\left(I_{J}\right)$ for residual errors, and a covariance matrix $\left(\sum^{z}\right)$ for instrument error. The value of $\sum^{z}$ was derived from 42 repeat analyses of a sediment standard on the XRFS instrument.

The complete Bayesian posterior distribution can be summarized as:

$$
\begin{aligned}
\mathrm{p}\left(\Sigma^{r e s z}, \mu, S, P, \Phi, \mu^{\Phi}, \sigma^{2 \Phi} \mid Y\right) \propto \mathrm{p}\left(Y \mid \mu, \quad \Sigma^{r e s z}\right) & \times \mathrm{p}\left(S \mid \mu^{s}, \quad \Sigma^{s}\right) \\
& \times \mathrm{p}\left(\Phi \mid \mu^{\Phi}, \quad \sigma^{2 \Phi}\right) \\
& \times \mathrm{p}\left(\Sigma^{r e s z}\right) \times \mathrm{p}\left(\mu^{\Phi}\right) \\
& \times \mathrm{p}\left(\sigma^{2 \Phi}\right)
\end{aligned}
$$

The mixing model was run for 750,000 iterations, with a 100,000 sample burn-in and jump length of 225 to minimize autocorrelation between runs. To confirm whether the MCMC random walk had converged on the equilibrium distribution, three MCMC chains were run in parallel from slightly different starting conditions so that trace plots of the parameter distributions could be inspected for evidence of mixing. The 'coda' package (Plummer et al., 2006) in the R environment was then used to perform convergence diagnostics.

In contrast to other sediment fingerprinting studies (e.g. Gellis and Noe, 2013; Thompson et al., 2013) no particle size corrections were incorporated within the model. This was because it was not possible to carry out a particle size analyses for every SPM sample with the small masses of sediment (often $<25 \mathrm{mg}$ ) that were collected and transferred directly onto filter papers. Organic matter corrections (e.g. Kim et al., 2013) were also omitted because difficulty in generalizing the relationships between organic matter and sediment geochemistry carries the risk of overcorrecting the data and thus leading to uncontrolled levels of uncertainty (Smith and Blake, 2014). Corrections for organic matter content are also more important when dealing with trace elements as opposed to the major elements employed here (Horowitz, 1991). In any case, if the actual source mixing processes that occurred in our study required such corrections, this model error would be implicitly wrapped up in the residual error distribution $\left(\sum^{\text {resz }}\right)$ in our results.

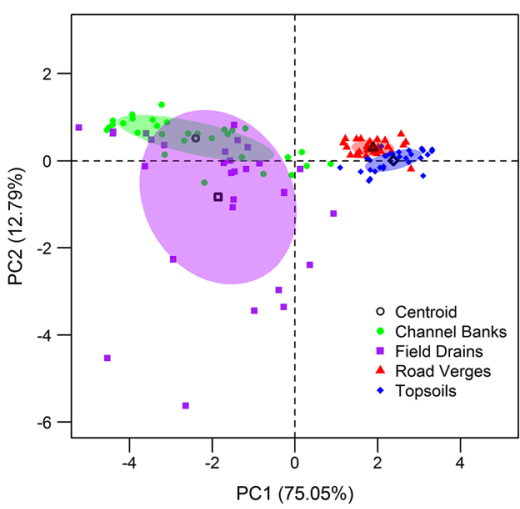

\section{Results}

\section{Discriminating sources}

Principal components analysis revealed strong contrasts between the geochemistry of surface and subsurface sediment sources that could largely be explained by the first two components (Figure 4). Principal component 1 (which explained $75.05 \%$ of data variance) highlighted calcium (Ca) as the most powerful discriminator of surface and subsurface sediments. This reflects the increase in $\mathrm{Ca}$ concentration with depth through the geological transition from carbonate-depleted surface deposits to chalky boulder clays at depths exceeding 0.5 $\mathrm{m}$. The second principal component (which explained $12.79 \%$ of data variance) emphasized the importance of iron (Fe) concentrations in differentiating between channel bank and field drain, and road verge and topsoil sediments, respectively. This was especially telling for field drains, where very high Fe concentrations (up to $22 \%$ ) were recorded at several locations, potentially indicating the localized oxidation and release of iron sulphides from the glacial till deposits. Despite this, there remained a significant overlap in the geochemical ranges of both channel bank and field drain sediments which made differentiation difficult. The geochemical data for channel banks and field drains were therefore merged into a combined 'subsurface' sediment source prior to running the apportionment model. The third principal component $(5.34 \%$ of the variance) weighed most heavily on sodium $(\mathrm{Na})$ as a discriminator of topsoil and road verge sources, and most likely reflects the higher $\mathrm{Na}$ concentrations in verge sediments as a result of winter road gritting with salts.

The Kruskal-Wallis $\mathrm{H}$-test and linear discriminant analysis revealed all geochemical fingerprints were significantly different between at least two source areas, and that Ca was the strongest discriminator, capable of successfully differentiating $79.2 \%$ of source area samples (Table II). Combined with the other seven elements, $97.5 \%$ of source area samples could be correctly identified. Whilst inclusion of $\mathrm{Fe}, \mathrm{Na}$ and titanium (Ti) did not improve the power of source discrimination, these additional fingerprints were still included in the mixing model based on previous research which demonstrated that, provided fingerprints are valid, maximizing the number of tracers in Bayesian mixing models can help to significantly improve differentiation and reduce model uncertainties (Parnell et al., 2010).

\section{Precipitation Event 1}

Precipitation Event 1 occurred during low flow conditions $(<0.25 \mathrm{~m}$ stage) on 4-5 October 2012, when $10.2 \mathrm{~mm}$ of

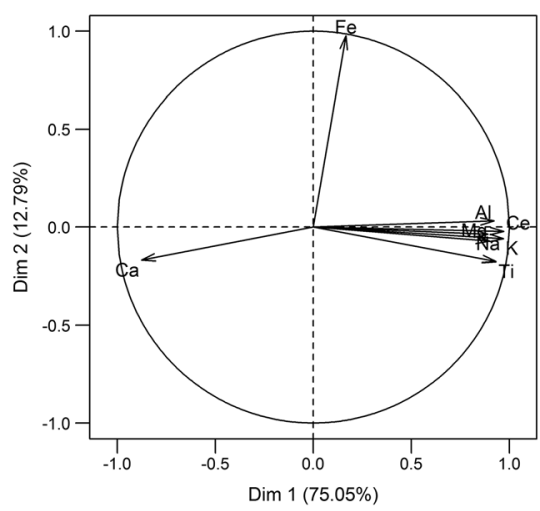

Figure 4. Principal component analysis plots of the source area samples (left) and fingerprint loadings (right) for the first two principal components. Shaded ellipsoids cover $50 \%$ of the source area range. This figure is available in colour online at wileyonlinelibrary.com/journal/espl 
Table II. Assessing the ability of the geochemical fingerprints to differentiate between sediment source areas via the Kruskal-Wallis $H$-test and minimization of Wilks-Lambda

\begin{tabular}{|c|c|c|c|c|c|c|}
\hline \multirow[t]{2}{*}{ Fingerprint property } & \multicolumn{2}{|c|}{ Kruskal-Wallis } & \multicolumn{4}{|c|}{ Minimization of Wilks-Lambda } \\
\hline & $H$-Value & $p$-Value & Selection step & Wilks-Lambda & Cumulative $p$-value & $\begin{array}{c}\text { Cumulative } \% \text { of source areas } \\
\text { correctly classified }\end{array}$ \\
\hline $\mathrm{Ca}$ & 101.96 & $<0.001$ & 1 & 0.1724 & $<0.001$ & 79.2 \\
\hline K & 96.42 & $<0.001$ & 2 & 0.0499 & $<0.001$ & 85.0 \\
\hline Mg & 82.41 & $<0.001$ & 3 & 0.0195 & $<0.001$ & 93.3 \\
\hline $\mathrm{Ce}$ & 91.85 & $<0.001$ & 5 & 0.0086 & $<0.001$ & 97.5 \\
\hline $\mathrm{Fe}$ & 25.91 & $<0.001$ & 6 & 0.0075 & $<0.001$ & 97.5 \\
\hline $\mathrm{Na}$ & 90.37 & $<0.001$ & 7 & 0.0075 & $<0.001$ & 97.5 \\
\hline $\mathrm{Ti}$ & 93.55 & $<0.001$ & 8 & 0.0066 & $<0.001$ & 97.5 \\
\hline
\end{tabular}

rainfall fell over seven hours (Figure 5). This resulted in the approximate export of $31.8 \mathrm{~kg}$ of SPM from the catchment (calculated using a stage-discharge rating curve), equating to a sediment loss of $0.06 \mathrm{~kg} \mathrm{ha}^{-1}$. Prior to event onset, SPM geochemistry was dominated by high Ca concentrations (24-26\%) and low concentrations of clay associated elements, such as $\mathrm{Al}(7-8 \%)$, Fe (6-7\%), Mg (0.6-0.7\%) and K (1.3-1.4\%). Such geochemistry is characteristic of material derived from deeper carbonate-rich subsurface sources located within the chalky, flint-rich boulder clays (Table I). The source apportionment model consequently estimated high median sediment contributions of 85 to $90 \%$ (60-99\% at the $95 \%$ credible interval) from eroding channel banks and agricultural field drains prior to event onset. As the weather front crossed the catchment, heavy rainfall increased runoff (Figure 2a), dislodging and transporting fine-grained, calcium carbonate depleted, surface source material to the river. This resulted in rapid increases in SPM concentrations of most elements, mirrored by a rapid decline in the proportion of $\mathrm{Ca}$. Elevated OC concentrations also indicated increased sediment input from organic matter rich surface sources (Jobbágy and Jackson, 2000). Accordingly, the mixing model estimated increased median contributions from both road verges (26-28\%) and topsoils (21-29\%) during the $2-3$ hour period post-heaviest rainfall, with proportions from subsurface sources correspondingly declining and closely matching falling Ca concentrations. However, uncertainties around apportionment estimates increased as SPM shifted towards a more carbonate-depleted geochemistry, with topsoil and road verge contributions having wide $95 \%$ credible intervals of 2 to $58 \%$ and 1 to $95 \%$, respectively. Essentially, difficulty in differentiating between the two surface sources meant the mixing model struggled to identify a unique solution. Note that these uncertainties are predominantly due to variability in source area geochemistry rather than instrument precision, which is small in comparison. Cessation of precipitation initiated a rapid return towards pre-event geochemical concentrations, with subsurface sources returning to being the major contributor of SPM (median 82-89\%) and uncertainty ranges for all sources reducing to less than $40 \%$. Over the entire event, estimated median (95\% credible interval) load weighted sediment contributions were $22.1 \mathrm{~kg}(12.8-29.5 \mathrm{~kg})$ from subsurfaces, $5.5 \mathrm{~kg}(0.4-12.7 \mathrm{~kg})$ from topsoils and $3.2 \mathrm{~kg}$ $(0.1-13.9 \mathrm{~kg})$ from road verges.

\section{Precipitation Events 2-4}

In late November 2012, three consecutive precipitation events of $15.8 \mathrm{~mm}, 8.4 \mathrm{~mm}$ and $12.2 \mathrm{~mm}$ occurred under high stream flow conditions ( $>0.5 \mathrm{~m}$ stage). This resulted in the measured transport of $4030 \mathrm{~kg}$ of SPM, equating to a catchment sediment loss of $7.5 \mathrm{~kg} \mathrm{ha}^{-1}$ (Figure 6). Prior to the onset of monitoring, stage and SPM concentrations were returning to baseflow levels following a previous rainfall event on 23 November (not captured). As successive rainfall events passed across the catchment, concentrations of OC and all elements excluding $\mathrm{Ca}$ increased, once again indicating the generation of surface runoff based on our knowledge of source area geochemistry (Table I). In contrast, Ca concentrations declined over the period signifying the reduced importance of subsurface sediment contributions during the succession of events. These major geochemical trends were echoed by the source apportionment model, with estimated subsurface contribution declining from a median $60 \%$ (44-76\% at the $95 \%$ credible interval) just prior to Event 2 onset, to a low of 30\% (15-46\%) after Events 3 and 4. However, it should be noted that whilst the proportions declined, actual masses of subsurface sediment increased during this time as the transport capacity of the stream increased. Pre-event median (95\% credible interval) topsoil and road verge contributions of 16 to $24 \%$ (5-46\%) and 22 to $31 \%$ (9-51\%), respectively, were higher than observed in October, a likely consequence of material still being in suspension from the prior 23 November event. With each passing precipitation front, topsoil and road verge contributions increased, reaching highs of $32 \%$ $(11-59 \%)$ and $38 \%(16-63 \%)$, respectively. Importantly, uncertainties around apportionment estimates were lower than that estimated for Event 1, indicating an improvement in the ability of the mixing model to differentiate between sources under these particular geochemical conditions. Median (95\% credible interval) load weighted contributions for all three events were $1584 \mathrm{~kg}(910-2337 \mathrm{~kg})$ from subsurfaces, $1075 \mathrm{~kg}(362-2053$ $\mathrm{kg}$ ) from topsoils, and $1304 \mathrm{~kg}$ (553-2224 kg) from road verges.

\section{Precipitation Event 5}

The temporal trends observed during the February 2013 event were very similar to the aforementioned precipitation episodes (Figure 7). A total of $12.8 \mathrm{~mm}$ of rainfall fell over a period of 10 hours, with changes in geochemistry discernible 90 minutes after event onset. In total, a measured $1444 \mathrm{~kg}$ of SPM were exported from the catchment during the monitoring period, equating to a sediment loss of $2.69 \mathrm{~kg} \mathrm{ha}^{-1}$. Passage of the weather front across the catchment was once again associated with an increase in all element concentrations excluding $\mathrm{Ca}$, indicating material travelling downstream at this time had a composition more typical of surface rather than subsurface sources. The peak in SPM concentrations approximately 45 minutes after the most intense rainfall strongly suggests surface runoff was being generated, accelerating the land-to-stream transfer of sediments. Topsoils were estimated to be the major contributing source of sediment (median $42-43 \%$ ) over the four hour period towards the middle and later stages of the event, 


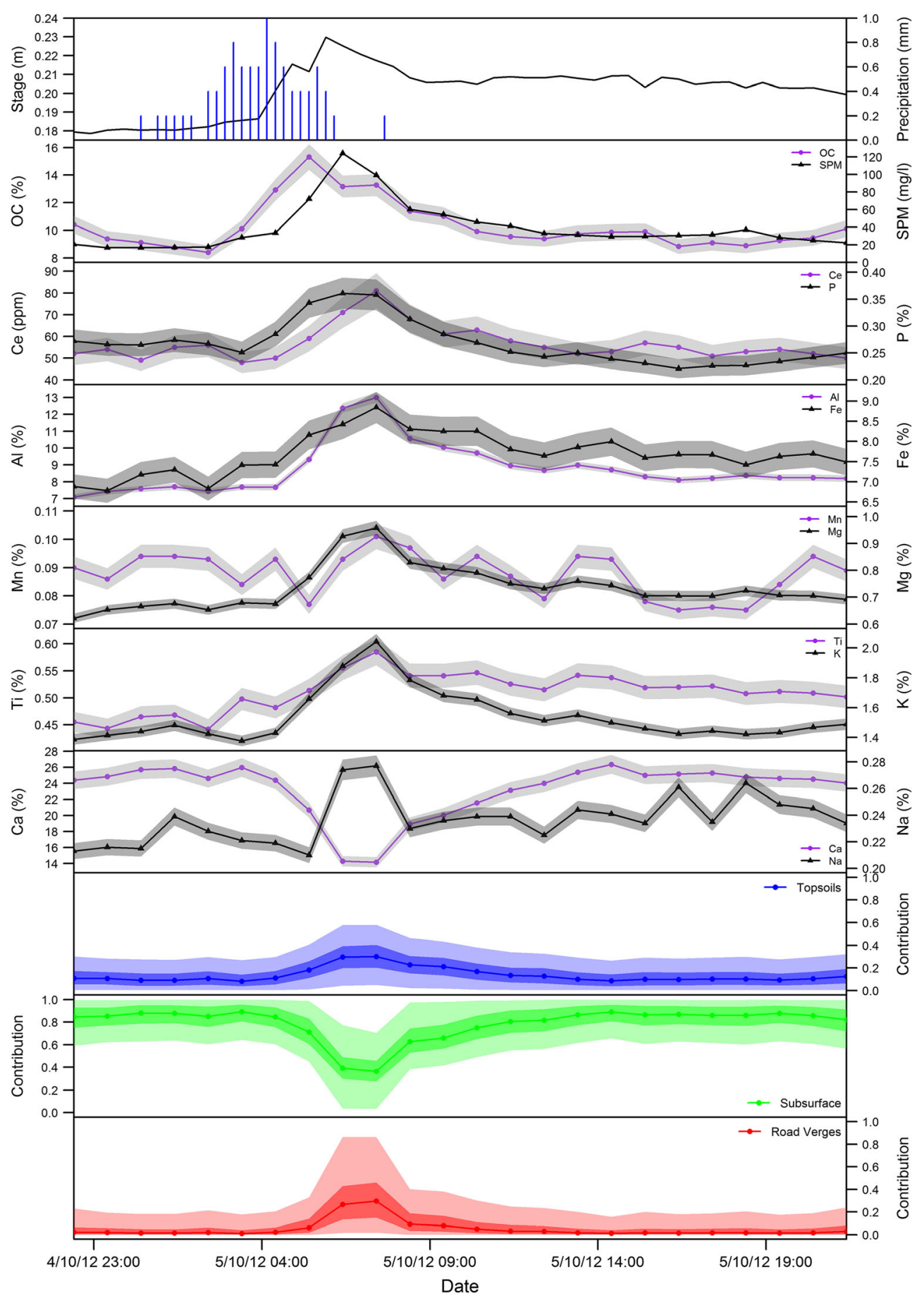

Figure 5. Time-series plots for the October 2012 precipitation event (Event 1), showing changing SPM geochemistry (\% by weight) and sediment source contributions at 60-minute intervals over a 24-hour period. Shading around geochemical parameters represents instrumental precision (two standard deviations) based on 46 repeat analyses of a control sample. Light and dark shading around median source apportionment estimates represent the $95 \%$ and $50 \%$ Bayesian credible intervals, respectively. This figure is available in colour online at wileyonlinelibrary.com/journal/espl

although wide $95 \%$ credible intervals $(8-78 \%)$ indicate high uncertainty. Median road verge contributions were estimated at between $37-40 \%$ during the peak in SPM concentrations, again with high uncertainty $(7-81 \%)$, whilst median subsurface contributions of 16 to $27 \%$ (9-48\%) were comparatively low. This high uncertainty during periods of carbonate-depleted sediment input into the stream further demonstrates the mixing model has difficultly in differentiating between the topsoil and road verge sediment during these periods. Cessation of precipitation and the decline in stage were once again associated with an increase in sediment contributions from subsurface sources, as indicated by the gradual rise in the Ca concentration back to pre-event levels. As with Events 1-4, the changing temporal contribution from subsurface sources mirrors that of $\mathrm{Ca}$ concentrations in
SPM. By the end of the monitoring period, SPM geochemistry had largely returned to pre-event concentrations, with a median $51 \%(31-73 \%)$ contribution from subsurface material outweighing contributions of $26 \%(8-50 \%)$ from road verges and $20 \%(4-43 \%)$ from topsoils. Load weighted contributions for the whole event were $519 \mathrm{~kg}(139-1026 \mathrm{~kg}), 479 \mathrm{~kg}(101-938 \mathrm{~kg})$ and $412 \mathrm{~kg}$ (178-699 kg) for road verges, topsoils and subsurface sources, respectively.

\section{Omitting fingerprints}

To explore the impact of including the three additional weak source discriminatory power fingerprints ( $\mathrm{Fe}, \mathrm{Na}$ and $\mathrm{Ti}$ ) in 


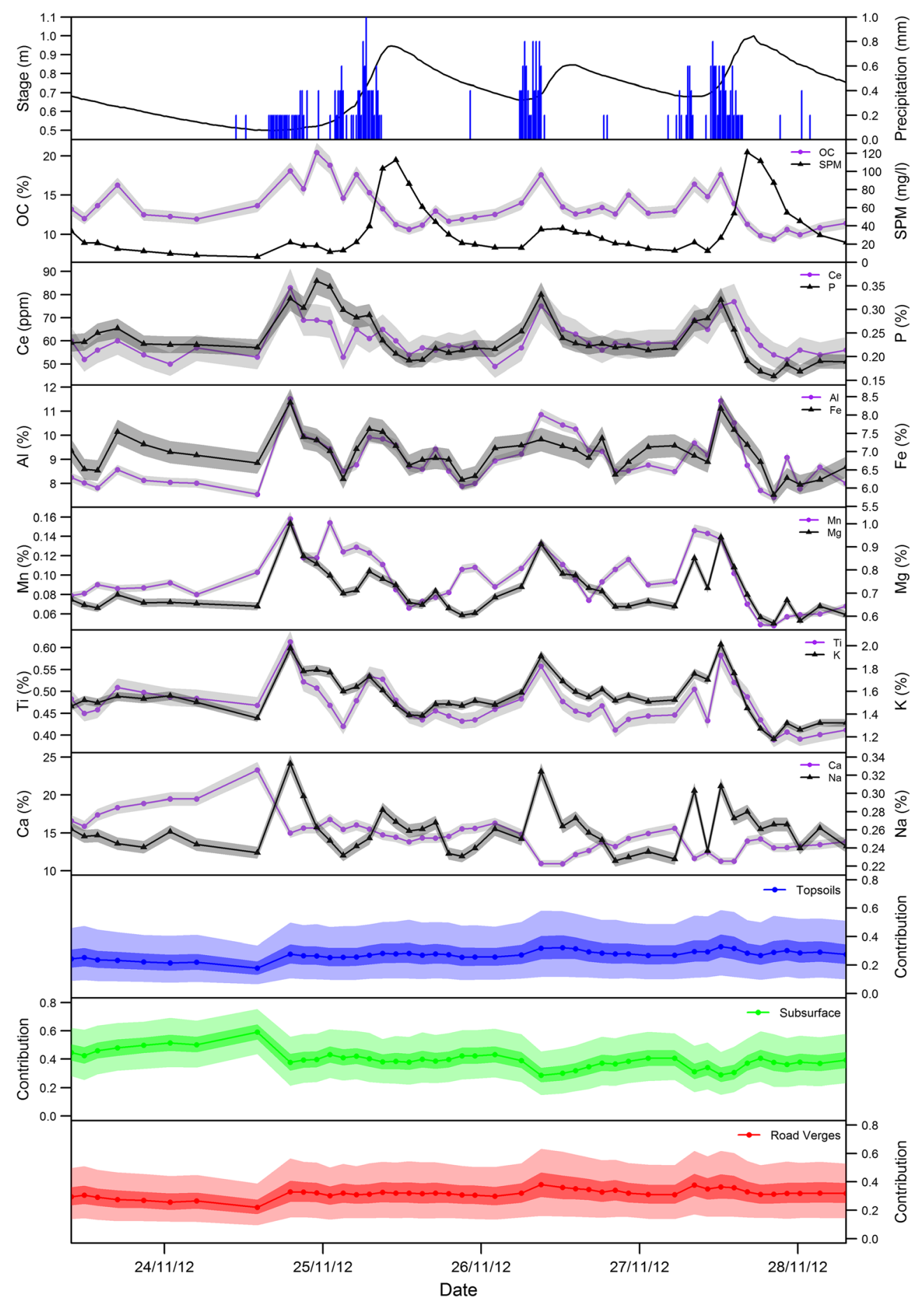

Figure 6. Time-series plots for three consecutive precipitation events in November 2012 (Events 2-4), showing changing SPM geochemistry (\% by weight) and sediment source contributions at 120-minute intervals over a 118-hour period. Shading around geochemical parameters represents instrumental precision (two standard deviations) based on 46 repeat analyses of a control sample. Light and dark shading around median source apportionment estimates represent the $95 \%$ and $50 \%$ Bayesian credible intervals, respectively. This figure is available in colour online at wileyonlinelibrary.com/journal/espl

the mixing model, the model was re-run for all five precipitation events using a reduced suite of just five tracers (AI, Ca, $\mathrm{Ce}, \mathrm{K}$ and $\mathrm{Mg}$ ). Although not shown here, the resulting November 2012 and February 2013 apportionment estimates of the five fingerprint model were broadly similar to the eight fingerprint model. That said, median source contribution estimates still varied by up to $6.9 \%$ across all sources relative to the eight fingerprint model, whilst credible interval widths increased across all sources by up to $9.9 \%$. Appointment results for the October 2012 event were even more heavily affected, with estimated median topsoil and road verge contribution during the $2-3$ hour period post-heaviest rainfall declining by $11.5 \%$ and $17.8 \%$, respectively, relative to the eight fingerprint model
(Figure 8). This was mirrored by a $28.3 \%$ increase in estimated median subsurface contribution. Uncertainty levels were similarly impacted, declining by $51 \%, 19.8 \%$ and $4 \%$ for road verge, subsurface and topsoil contributions, respectively. Such large changes demonstrate that whilst only five fingerprints were required to successfully differentiate the three source areas (Table II), the additional three fingerprints still contained important information capable of significantly influencing source apportionment estimates. As previously reported (e.g. Parnell et al., 2010; Dutton et al., 2013), it is therefore advantageous to maximize the number of fingerprints incorporated into Bayesian mixing models as any tracer has the potential to assist with source mixing if, for example, the mixing 


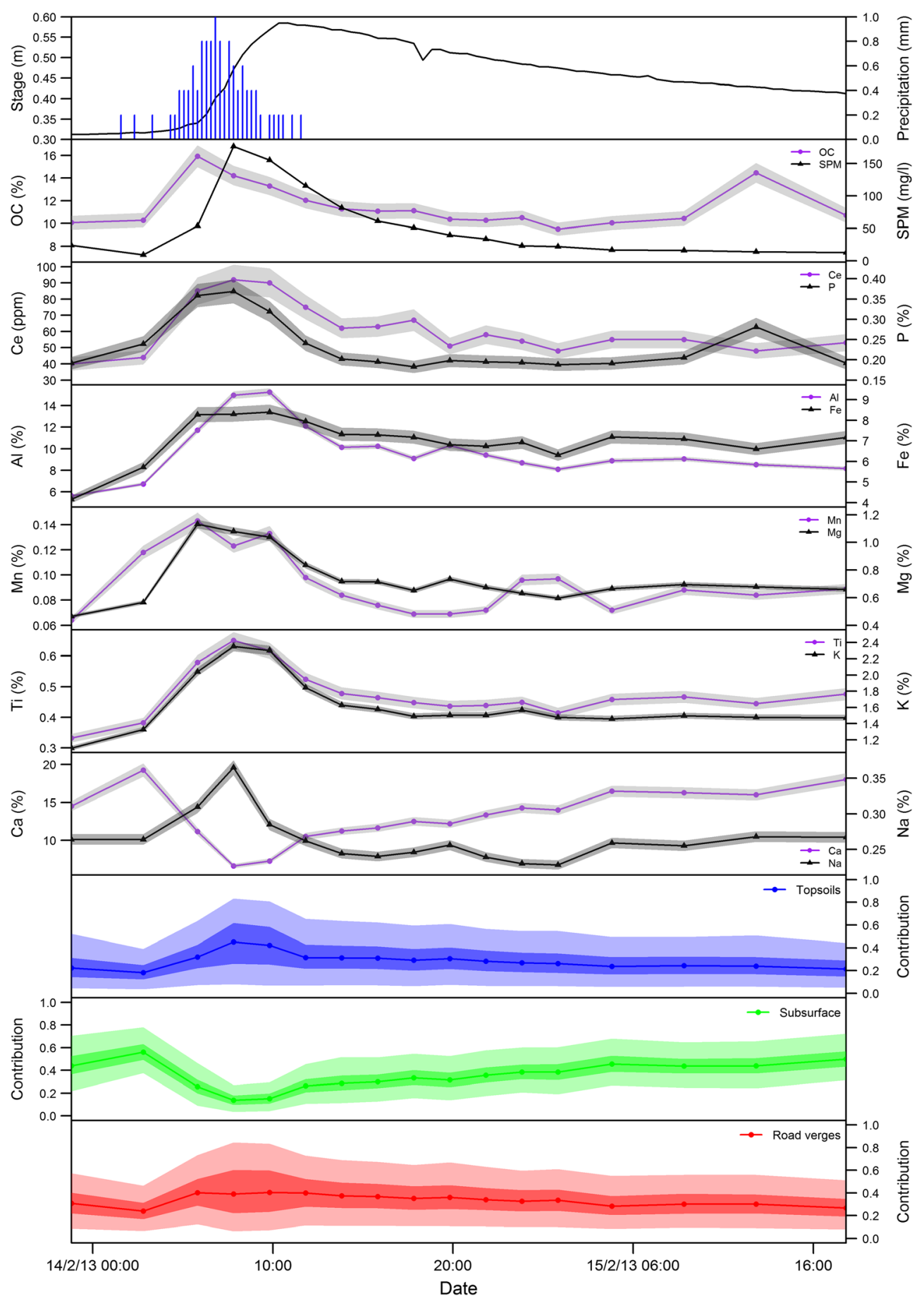

Figure 7. Time-series plots for the February 2013 precipitation event (Event 5), showing changing SPM geochemistry (\% by weight) and sediment source contributions at 120-minute intervals over a 48-hour period. Shading around geochemical parameters represents instrumental precision (two standard deviations). Light and dark shading around median source apportionment estimates represent the $95 \%$ and $50 \%$ Bayesian credible intervals, respectively. This figure is available in colour online at wileyonlinelibrary.com/journal/espl

processes for one particular tracer are different from the others. If additional fingerprints genuinely contribute limited information to aid source apportionment, they will exert only minor influence on the resulting posterior distributions.

\section{Discussion}

\section{Catchment connectivity}

The temporal fluctuations observed in SPM geochemistry during all five precipitation events indicate that lower flow, nonevent conditions are characterized by subsurface erosion of the Mid-Pleistocene chalky, flint-rich boulder clays, with limited sediment input from surface sources. This situation is reversed during precipitation events, with SPM shifting towards the more organic matter and clay mineral-rich, Ca-depleted geochemistry characteristic of surface soils. Importantly, the Bayesian mixing model has been able to successfully translate these geochemical trends into estimated sediment volumes originating from each of the three sources within a realistic uncertainty range. The apportionment results also correspond favourably with our knowledge of both catchment geology and connectivity of source areas to the stream channel.

However, due to sediment storage on the streambed over time, caution should be exercised when attempting to relate these high-resolution apportionment estimates directly to catchment erosion processes for a given event (Gellis and 


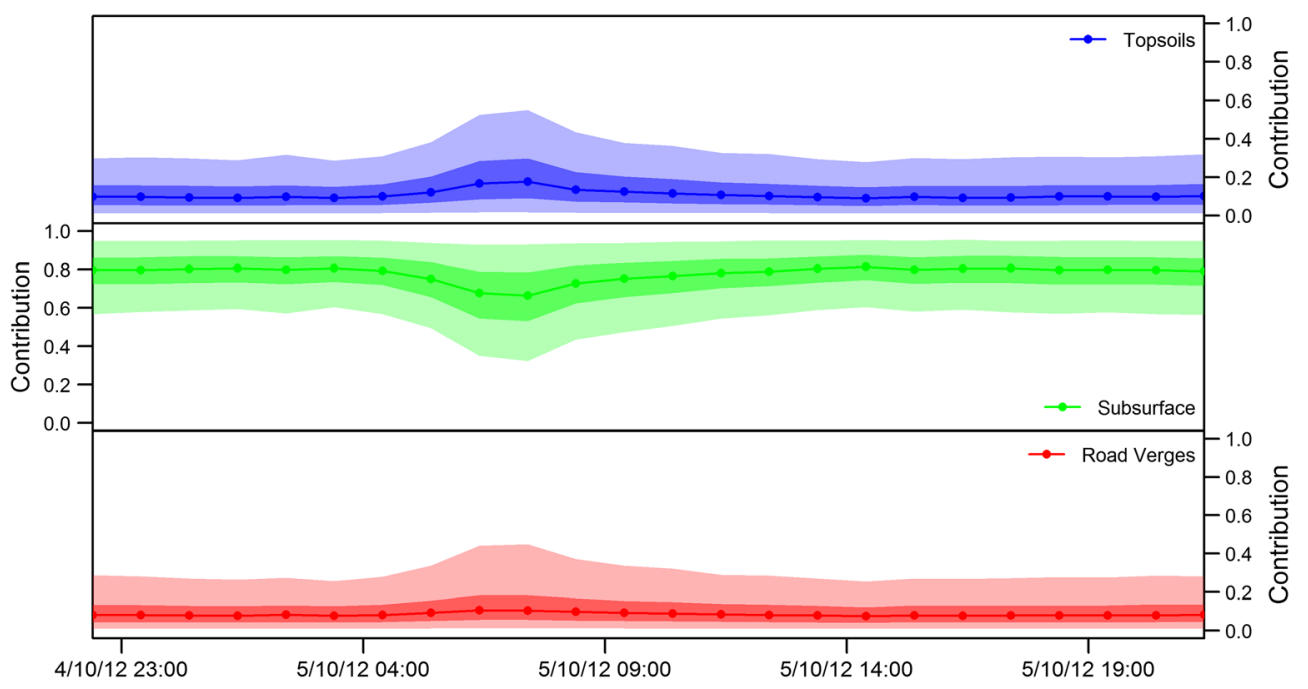

Figure 8. Sediment source apportionment results for the October 2012 precipitation event (Event 1) when employing a five fingerprint (Al, Ca, Ce, K, $\mathrm{Mg}$ ) Bayesian mixing model. Light and dark shading around median source apportionment estimates represent the 95\% and 50\% Bayesian credible intervals, respectively. This figure is available in colour online at wileyonlinelibrary.com/journal/espl

Noe, 2013). For example, whilst sediment contributions from surface sources remained relatively high some 30 hours after precipitation had ceased during the February 2013 event (Event 5), this does not imply that surface runoff was still occurring. Indeed, visual inspection of the catchment revealed it to have ceased many hours before. Instead, this represents the continual resuspension of surface source sediments from the streambed, not just from this event, but previous events that occurred during the winter of 2012/2013.

Furthermore, whilst the mixing model provides quantitative estimates of sediment volumes derived from all road verge and topsoil sources, visual observations suggest that sediments mobilized during rainfall events are dominantly transported to the river from a few critical source areas (Thompson et al., 2012). These are the damaged field entrances, tramlines and narrow road sections that occupy relatively small areas of the catchment. In particular, peaks in estimated road verge contribution during all precipitation events indicate that land-to-river connectivity involves metalled roads which direct sedimentladen water downhill to a drain at a road bridge that discharges directly into the stream (Figure 2a). Sediment concentrations in this road runoff have regularly been measured at between 400 and $1500 \mathrm{mg} \mathrm{I}^{-1}$ and flowing at rates far exceeding $1.5 \mathrm{I} \mathrm{s}^{-1}$. This issue surrounding the role of roads and roadside ditches in increasing the hydrological connectivity between agricultural fields and streams has previously been discussed by Buchanan et al. (2012) and Boardman (2013), for example. In the Blackwater catchment, the October and November precipitation events (Events 1-4) also coincided with the sugar beet harvest, and topsoil material was observed washing off a concrete sugar beet storage area downslope to the river. A useful development focus for future research would be to quantitatively apportion sediments derived from each of these critical source areas to improve the targeting of mitigation measures, rather than simply using the two main source categories (road verges and topsoils) we used here. However, achieving such an increase in spatial resolution would require an extended suite of tracers when one considers the large uncertainties produced when attempting to differentiate between just these two broad source categories. Had road verge and topsoil sediments been more geochemically distinct, source discrimination could have been improved and model uncertainties reduced (e.g. Small et al., 2002; Dutton et al., 2013).

\section{Hysteresis behaviour}

Additional supporting information for the mixing model source apportionment results can be obtained from an examination of sediment-discharge relationships for each precipitation event (e.g. Lefrançois et al., 2007; Krueger et al., 2012; Navratil et al., 2012). All five of the events monitored here exhibited either clockwise or near symmetric hysteresis loops, with SPM concentrations higher on the rising limb of the hydrograph than the corresponding falling limb (Figure 9). Such clockwise hysteretic behaviour is thought to be indicative of high energy systems with an initially unrestricted sediment supply in close proximity to the stream channel that quickly becomes exhausted by flushing and cannot easily be replaced (Williams, 1989). This corresponds well with the notion of road runoff being a major sediment pathway in the Blackwater catchment. The road bridge where sediment ingress occurs is located just $670 \mathrm{~m}$ upstream of monitoring station $\mathrm{A}$, and surface runoff over the impermeable metalled road is generated rapidly after the onset of heavy precipitation. Once precipitation has ended, road runoff ceases shortly afterwards and does not recommence until the next rainfall period, hence generating the characteristic clockwise hysteric behaviour.

\section{Implications for catchment management}

These source appointment results provide quantitative confirmation that precipitation events within the Blackwater catchment are associated with an increase in surface land-to-river sediment transfer. Considering their relatively small spatial extent, contributions from road verges $(13-59 \%$ of all SPM transported during the five events based on $95 \%$ credible intervals) are particularly significant sediment sources, albeit with large uncertainty, supporting previous findings made by Collins et al. (2010, 2013b). Therefore, mitigation measures targeted at reducing the connectivity of these critical source areas, such as by installing roadside sediment traps, improving sugar beet storage practices and minimizing agricultural machinery movement on and off fields during wet weather, would likely prove to be the most effective management techniques to reduce fluvial sediment ingress from the terrestrial environment. Additionally, a previous study by Rawlins et al. (2013) demonstrated that aggregates of topsoils across the Blackwater sub-catchment have lower stability in comparison to other 


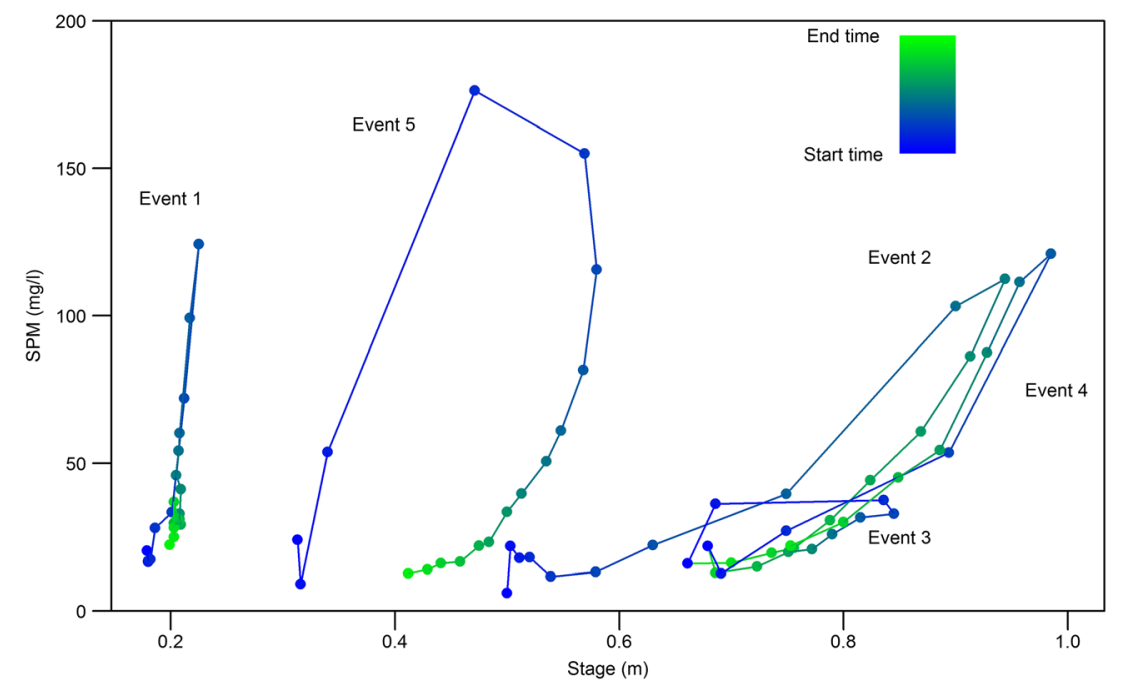

Figure 9. Hysteresis plots of SPM versus stage for the five monitored precipitation events. This figure is available in colour online at wileyonlinelibrary.com/journal/espl

agricultural soils in eastern England, in part due to the low organic matter content of the former. By applying organic amendments to increase the concentration of organic matter in topsoils, it may be possible to improve aggregate stability and limit the delivery of fine material to the channel network. With a median $63 \%$ (44-80\% at the $95 \%$ credible interval) of SPM derived from surface sources during the October, November and February events (Events 1-5), up to $3386 \mathrm{~kg}$ (2442-4407 $\mathrm{kg}$ ) of fine sediment could, theoretically, have been prevented from entering the stream with appropriately targeted mitigation measures.

\section{Methodological advantages}

Although other studies have used infrared spectroscopy to analyse SPM-covered filter papers (e.g. Martínez-Carreras et al., 2010b; Tremblay et al., 2011), this contribution represents the first successful attempt at using direct XRFS analysis of SPM-covered filter papers for sediment source apportionment modelling. Because the method is non-destructive, costeffective, time-efficient and can be used in conjunction with automatic samplers, the procedure is conducive to this type of high-temporal resolution monitoring where large numbers of samples need to be analysed. Furthermore, because only 5 $\mathrm{mg}$ of sediment are required to yield accurate results for a wide array of elemental parameters (Cooper et al., 2014), it is particularly beneficial in environments where SPM concentrations can be too low $\left(<100 \mathrm{mg} \mathrm{I}^{-1}\right)$ for traditional analysis without bulking water samples. The result is that source apportionment estimates can be generated at a high-temporal resolution that is simply not possible when using time-integrated samplers or single-point grab samples (e.g. Poulenard et al., 2009). A good example of how the temporal sampling resolution can affect resulting source apportionment estimates is by comparison with Collins et al. (2013a), who carried out a separate lowtemporal resolution sediment fingerprinting procedure within the Wensum DTC area. In contrast to our high-resolution approach, Collins et al. (2013a) collected streambed sediment samples from three locations in the River Blackwater on a bimonthly basis. Whilst results are not directly comparable due to differences in the location of sediment sampling within the catchment, Collins et al. (2013a) estimated the topsoil contribution $(\sim 58-70 \%)$ to be much greater than that for channel banks $(\sim 19-30 \%)$ or road verges $(\sim 6-23 \%)$ during all months, with apportionment showing relatively little monthly variability. In contrast, our approach demonstrates significant variability in source contributions at 60- to 120-minute intervals during the transition from low- to high-flow conditions, and emphasizes that surface sediments are dominant sources for only a few hours during rainfall events when the highest sediment loads are recorded. This more precise knowledge of when, and for how long after rainfall, surfaces sources are dominant is beneficial when attempting to identify the locations of critical source areas.

The other major advantage of the approach presented here arises from setting source apportionment within a Bayesian uncertainty framework. Other traditional fingerprinting studies (e. g. Motha et al., 2003; Wilkinson et al., 2013) often present uncertainties around apportionment estimates in ad hoc ways which do not fully and consistently represent the spatial variability in fingerprint properties across the catchment, uncertainties associated with instrumental precision, covariance between fingerprint properties, nor residual model error. In contrast, we have been able to provide a full and coherent characterization of all these factors by employing a Bayesian mixing model procedure. The resulting distributions, while often large, are nevertheless a realistic reflection of the often unavoidable uncertainties associated with sediment source apportionment estimates.

\section{Conclusions}

In this contribution, we have addressed two key developments of sediment fingerprinting research. Namely, how to improve the temporal resolution of source apportionment estimates, and how to coherently quantify all perceived uncertainties associated with the mixing model procedure. By combining the direct XRFS and DRIFTS analysis of SPM-covered filter papers with automatic water samplers, we have been able to observe temporal fluctuations in SPM geochemistry at 60- to 120mintue resolution during the progression of five precipitation events in the Blackwater sub-catchment of the River Wensum, Norfolk. These high-resolution geochemical time series reveal that SPM under lower flow, non-event conditions is dominated by high Ca concentrations, indicating erosion of the subsurface Mid-Pleistocene chalky, flint-rich boulder clays dominates during these periods, with limited sediment input from surface sources. This situation is reversed during precipitation events, 
with SPM shifting towards a more organic matter and clay mineral-rich, Ca-depleted geochemistry characteristic of surface soils. By employing a Bayesian mixing model procedure, we have then been able to successfully translate these geochemical trends into quantitative estimates of sediment volumes originating from three main source areas, namely topsoils, road verges and subsurfaces. Importantly, the adoption of a Bayesian approach has allowed for full characterization of spatial geochemical variability, instrument precision and residual error to yield a realistic and coherent assessment of the uncertainties associated with source apportionment estimates. Over the five rainfall events, $63 \%(44-80 \%$ at the $95 \%$ credible interval) of SPM was derived from surface sources, equating to a total land-to-river sediment transfer of 3386 kg (2442-4407 $\mathrm{kg})$, with road verges $(13-59 \%)$ in particular proving to be a highly important source. The importance of maximizing the number of tracers incorporated into Bayesian mixing models has also been highlighted, with median source appointment estimates varying by up to $28.3 \%(51.4 \%$ at the $95 \%$ credible interval) depending on whether five or eight fingerprints were included. Overall, the results presented here demonstrate the benefits that high-resolution SPM monitoring and Bayesian uncertainty assessment bring to our understanding of catchment processes. Further source apportionment investigations using the same monitoring techniques employed here will assist with the appropriate targeting of sediment pollution mitigation measures at a catchment level.

Acknowledgements — This work was carried out as part of the Wensum Demonstration Test Catchment project funded by Defra (WQ0212). The authors would like to thank Bertrand Lézé for running the XRFS analysis, Andrew Parnell for assistance with the Bayesian modelling, Gilla Suennenberg for GIS mapping and Jenny Stevenson and Zanist Hama-Aziz for fieldwork support. Discussions with Stephen Haley and Rachael Macrorie proved helpful. The authors also thank three anonymous reviewers whose constructive comments helped improve this manuscript. RJC acknowledges financial support from a NERC BGS CASE studentship (NE/J500069/1). TK acknowledges funding from the German Excellence Initiative.

\section{References}

Acornley RM, Sear DA. 1999. Sediment transport and siltation of brown trout (Salmo trutta L.) spawning gravels in chalk streams. Hydrological Processes 13: 447-458. DOI. 10.1002/(SICl)1099-1085 (19990228)13:3<447::AID-HYP749>3.0.CO;2-G

Bilotta GS, Brazier RE. 2008. Understanding the influence of suspended solids on water quality and aquatic biota. Water Research 42: 28492861. DOI. 10.1016/j.watres.2008.03.018

Blake WH, Ficken KJ, Taylor P, Russell MA, Walling DE. 2012. Tracing crop-specific sediment sources in agricultural catchments. Geomorphology 139-140: 322-329. DOI. 10.1016/j.geomorph.2011.10.036

Boardman J. 2013. The hydrological role of 'sunken lanes' with respect to sediment mobilization and delivery to watercourses with particular reference to West Sussex, southern England. Journal of Soil and Sediments 13: 163-1644. DOI. 10.1007/s11368-013-0754-7

Buchanan BP, Falbo K, Schneider RL, Easton ZM, Walter MT. 2012. Hydrological impact of roadside ditches in an agricultural watershed in central New York: implications for non-point source pollutant transport. Hydrological Processes 27: 2422-2437. DOI. 10.1002/ hyp.9305

Collins AL, Walling DE, Leeks GJL. 1997. Source type ascription for fluvial suspended sediment based on a quantitative composite fingerprinting technique. Catena 29: 1-27. DOI. 10.1016/S0341-8162 (96)00064-1

Collins AL, Walling DE, Stroud RW, Robson M, Peet LM. 2010. Assessing damaged road verges as a suspended sediment source in the Hampshire Avon catchment, southern United Kingdom. Hydrological Processes 24: 1106-1122. DOI. 10.1002/hyp.7573
Collins AL, Zhang YS, Hickinbotham R, Bailey G, Darlington S, Grenfell SE, Evans R, Blackwell M. 2013a. Contemporary fine-grained bed sediment sources across the River Wensum Demonstration Test Catchment, UK. Hydrological Processes 27: 857-884. DOI. 10.1002/hyp.9654

Collins AL, Zhang YS, Duethmann D, Walling DE, Black KS. 2013b. Using a novel tracing-tracking framework to source fine-grained sediment loss to watercourses at sub-catchment scale. Hydrological Processes 27: 959-974. DOI. 10.1002/hyp.9652

Cooper RJ, Rawlins BG, Lézé B, Krueger T, Hiscock K. 2014. Combining two filter paper-based analytical methods to monitor temporal variations in the geochemical properties of fluvial suspended particulate matter. Hydrological Processes 28: 4042-4056. DOI. 10.1002/hyp.9945

D'Haen K, Verstraeten G, Dusar B, Degryse P, Haex J, Waelkens M. 2012. Unravelling changing sediment sources in a Mediterranean mountain catchment: a Bayesian fingerprinting approach. Hydrological Processes 27: 896-910. DOI. 10.1002/hyp.9399

Dutton C, Anisfeld SC, Ernstberger H. 2013. A novel sediment fingerprinting method using filtration: application to the Mara River, East Africa. Journal of Soils and Sediments 13: 1708-1723. DOI. 10.1007/s11368-013-0725-z

Egozcue J, Pawlowsky-Glahn V, Mateu-Figueras G, Barceló-Vidal C. 2003. Isometric logratio transformations for compositional data analysis. Mathematical Geology 35: 279-300. DOI. 10.1023/A:1023818214614

Environment Agency. 2009. Water for Life and Livelihood: River Basin Management Plan - Anglian River Basin District. Environment Agency: Bristol; 68.

Evans DJ, Johnes PJ, Lawrence DS. 2004. Physico-chemical controls on phosphorus cycling in two lowland streams. Part 2 - the sediment phase. Science of the Total Environment 329: 165-182. DOI. 10.1016/j.scitotenv.2004.02.023

Evrard O, Navratil O, Ayrault S, Ahmadi M, Némery J, Legout C, Lefèvre I, Poirel A, Bonté P, Esteves M. 2011. Combining suspended sediment monitoring and fingerprinting to determine the spatial origin of fine sediment in a mountainous river catchment. Earth Surface Processes and Landforms 36: 1072-1089. DOI. 10.1002/esp.2133

Evrard O, Poulenard J, Némery J, Ayrault S, Gratiot N, Duvert C, Prat C, Lefèvre I, Bonté P, Esteves M. 2013. Tracing sediment sources in a tropical highland catchment of central Mexico by using conventional and alterative fingerprinting methods. Hydrological Processes 27: 911-922. DOI. 10.1002/hyp.9421

Fox JF, Papanicolaou AN. 2008. An un-mixing model to study watershed erosion processes. Advances in Water Resources 31: 96-108. DOI. 10.1016/j.advwatres.2007.06.008

Gellis AC, Noe GB. 2013. Sediment source analysis in the Linganore Creek watershed, Maryland, USA, using the sediment fingerprinting approach: 2008 to 2010. Journal of Soils and Sediments 13: 1735-1753. DOI. 10.1007/s11368-013-0771-6

Gruszowski KE, Foster IDL, Lees JA, Charlesworth SM. 2003. Sediment sources and transport pathways in a rural catchment, Herefordshire, UK. Hydrological Processes 17: 2665-2681. DOI. 10.1002/hyp.1296

Hancock GJ, Revill AT. 2013. Erosion source discrimination in a rural Australian catchment using compound-specific isotope analysis (CSIA). Hydrological Processes 27: 923-932. DOI. 10.1002/hyp.9466

Hilton J, O'Hare M, Bowes MJ, Jones Jl. 2006. How green is my river? A new paradigm of eutrophication in rivers. Science of the Total Environment 365: 66-83. DOI. 10.1016/j.scitotenv.2006.02.055

Hiscock KM. 1993. The influence of pre-Devensian glacial deposits on the hydrogeochemistry of the chalk aquifer system of north Norfolk, UK. Journal of Hydrology 144: 335-369. DOI. 10.1016/0022-1694(93)90179-D

Hiscock KM, Dennis PF, Saynor PR, Thomas MO. 1996. Hydrochemical and stable isotope evidence for the extent and nature of the effective Chalk aquifer of north Norfolk, UK. Journal of Hydrology 180: 79-107. DOI. 10.1016/0022-1694(95)02895-1

Hopkins JB III, Ferguson JM. 2012. Estimating the diets of animals using stable isotopes and a comprehensive Bayesian mixing model. PLoS ONE 7: e28478. DOI. 10.1371/journal.pone.0028478

Horowitz AJ. 1991. A primer on sediment-trace element chemistry, 2nd edn, United States Geological Survey open-file report 91-76. US Geological Survey: Reston, VA.

House WA, Denison FH, Armitage PD. 1995. Comparison of the uptake of inorganic phosphorus to a suspended and stream bed-sediment. Water Research 29: 767-779. DOI. 10.1016/0043-1354(94)00237-2 
Huisman NLH, Karthikeyan KG. 2012. Using radiometric tools to track sediment and phosphorus movement in an agricultural watershed. Journal of Hydrology 450-451: 219-229. DOI. 10.1016/j. jhydrol.2012.05.007

Jobbágy EG, Jackson RB. 2000. The vertical distribution of soil organic carbon and its relation to climate and vegetation. Ecological Applications 10: 423-436. DOI. 10.1890/1051-0761(2000)010

Kim JK, Onda Y, Yang D-Y, Kim MS. 2013. Temporal variations of reservoir sediment sources in a small mountainous catchment in Korea. Earth Surface Processes and Landforms 38: 1380-1392. DOI. 10.1002/esp.3379

Krueger T, Quinton JN, Freer J, Macleod CJA, Bilotta GS, Brazier RE, Hawkins JMB, Haygarth PM. 2012. Comparing empirical models for sediment and phosphorus transfer from soils to water at field and catchment scale under data uncertainty. European Journal of Soil Science 63: 211-223. DOI. 10.1111/j.1365-2389.2011.01419.x

Lefrançois J, Grimaldi C, Gascuel-Odoux C, Gilliet N. 2007. Suspended sediment and discharge relationships to identify bank degradation as a main sediment source on small agricultural catchments. Hydrological Processes 21: 2923-2933. DOI. 10.1002/hyp.6509

Legout C, Poulenard J, Nemery J, Navratil O, Grangeon T, Evrard O, Esteves M. 2013. Quantifying suspended sediment sources during runoff events in headwater catchments using spectrocolorimetry. Journal of Soils and Sediments 13: 1478-1492. DOI. 10.1007/ s11368-013-0728-9

Lewis MA. 2011. Borehole Drilling and Sampling in the Wensum Demonstration Test Catchment, British Geological Survey Commissioned Report, CR/11/162. British Geological Survey: London; 38.

Martínez-Carreras N, Udelhoven T, Krein A, Gallart F, Iffly JF, Ziebel J, Hoffmann L, Pfister L, Walling DE. 2010a. The use of sediment colour measured by diffuse reflectance spectrometry to determine sediment sources: application to the Attert River catchment (Luxembourg). Journal of Hydrology 382: 49-63. DOI. 10.1016/j. jhydrol.2009.12.017

Martínez-Carreras N, Krein A, Udelhoven T, Gallart F, Iffly JF, Hoffmann L, Pfister L, Walling DE. 2010b. A rapid spectral-reflectance-based fingerprinting approach for documenting suspended sediment sources during storm runoff events. Journal of Soils and Sediments 10: 400-413. DOI. 10.1007/s11368-009-0162-1

Massoudieh A, Gellis A, Banks WS, Wieczorek ME. 2012. Suspended sediment source apportionment in Chesapeake Bay watershed using Bayesian chemical mass balance receptor modelling. Hydrological Processes. DOI. 10.1002/hyp.9429

Matsumoto K, Kawamura K, Uchida M, Shibata Y. 2007. Radiocarbon content and stable carbon isotopic ratios of individual fatty acids in subsurface soil: implications for selective microbial degradation and modification of soil organic matter. Geochemical Journal 41: 483-492. DOI. 10.2343/geochemj.41.483

Meteorological Office. 2013. UK Climate Averages: Reepham 19812010. Meteorological Office: Exeter. http://www.metoffice.gov.uk/ public/weather/climate/\#?tab=climateTables

Motha JA, Wallbrink PJ, Hairsine PB, Grayson RB. 2003. Determining the sources of suspended sediment in a forested catchment in southeastern Australia. Water Resources Research 39: 1-14. DOI. 10.1029/2001WR000794

Navratil O, Evrard O, Esteves M, Legout C, Ayrault S, Némery J, MateMarin A, Ahmadi M, Lefèvre I, Poirel A, Bonté P. 2012. Temporal variability of suspended sediment sources in an alpine catchment combining river/rainfall monitoring and sediment fingerprinting. Earth Surface Processes and Landforms 37: 828-846. DOI. 10.1002/ esp.3201

Olley J, Brooks A, Spenser J, Pietsch T, Borombovits D. 2013. Subsoil erosion dominates the supply of fine sediment to rivers draining into Princess Charlotte Bay, Australia. Journal of Environmental Radioactivity 124: 121-129.

Owens PN, Petticrew EL, van der Perk M. 2010. Sediment response to catchment disturbances. Journal of Soils and Sediments 10: 591-596.

Palmer MJ, Douglas GB. 2008. A Bayesian statistical model for end member analysis of sediment geochemistry, incorporating spatial dependences. Applied Statistics 57: 313-327.

Parnell AC, Inger R, Bearhop S, Jackson AL. 2010. Source partitioning using stable isotopes: coping with too much variation. PLOS ONE 5: e9672. DOI. 10.1371/journal.pone.0009672
Parnell AC, Phillips DL, Bearhop S, Semmens BX, Ward EJ, Moore JW, Jackson AL, Inger R. 2013. Bayesian stable isotope mixing models. Environmetrics 24: 387-399. DOI. 10.1002/env.2221

Phillips JM, Russell MA, Walling DE. 2000. Time-integrated sampling of fluvial suspended sediment: a simple methodology for small catch catchments. Hydrological Processes 14: 2589-2602. DOI. 10.1002/ 10991085(20001015)14:14<2589::AID-HYP94>3.0.CO;2-D

Plummer M. 2003. JAGS: a program for analysis of Bayesian graphical models using Gibbs sampling. Proceeding of the 3rd International Workshop on Distributed Statistical Computing, Vienna, Austria.

Plummer M, Best N, Cowles K, Vines K. 2006. R Package 'coda': convergence diagnosis and output analysis for MCMC. $R$ News 6(1): 7-11.

Poulenard J, Legout C, Némery J, Bramorski J, Navratil O, Douchin A, Fanget B, Perrette Y, Evrard O, Esteves M. 2012. Tracing sediment sources during floods using Diffuse Reflectance Infrared Fourier Transform Spectrometry (DRIFTS): a case study in a highly erosive mountainous catchment (southern French Alps). Journal of Hydrology 414-415: 452-462. DOI. 10.1016/j.jhydrol.2011.11.022

Poulenard J, Perrette Y, Fanget B, Quetin P, Trevisan D, Dorioz JM. 2009. Infrared spectroscopy tracing of sediment sources in a small rural watershed (French Alps). Science of the Total Environment 407: 2808-2819. DOI. 10.1016/j.scitotenv.2008.12.049

Pretty JN, Mason CF, Nedwell DB, Hine RE, Leaf S, Dils R. 2003. Environmental costs of freshwater eutrophication in England and Wales. Environmental Science and Technology 37: 201-208. DOI. 10.1021/es020793k

R Development Core Team. 2013. R: A Language and Environment for Statistical Computing. R Foundation for Statistical Computing: Vienna. http://www.R-project.org.

Rawlins BG. 2011. A Pilot Study to Assess Soil Spectroscopic Methods for Mapping Key Topsoil Properties in the Blackwater Subcatchments (Wensum DTC), British Geological Survey Internal Report, OR/11/053. British Geological Survey: London; 19 pp.

Rawlins BG, Wragg J, Lark RM. 2013. Application of a novel method for soil aggregate stability measurement by laser granulometry with sonication. European Journal of Soil Science 64: 92-103. DOI. 10.1111/ejss.12017

Rowan JS, Black S, Franks SW. 2011. Sediment fingerprinting as an environmental forensics tool explaining cyanobacteria blooms in lakes. Applied Geography 32: 832-843. DOI. 10.1016/j.apgeog.2011.07.004

Russell MA, Walling DE, Hodgkinson RA. 2001. Suspended sediment sources in two small lowland agricultural catchments in the UK. Journal of Hydrology 252: 1-24. DOI. 10.1016/S0022-1694(01)00388-2

Sear DA, Newson M, Old JC, Hill C. 2006. Geomorphological appraisal of the River Wensum Special Area of Conservation, English Nature Research Reports, No 685. Natural England: Sheffield.

Semmens BX, Ward EJ, Moore JW, Darimont CT. 2009. Quantifying inter- and intra-population niche variability using hierarchical Bayesian stable isotope mixing models. PLoS ONE 4: e6187. DOI. 10.1371/journal.pone.0006187

Schindler Wildhaber Y, Liechti R, Alewell C. 2012. Organic matter dynamics and stable isotope signature as tracers of the sources of suspended sediment. Biogeosciences 9: 1985-1996. DOI. 10.5194/ bg-9-1985-2012

Slimane AB, Raclot D, Evrard O, Sanaa M, Lefèvre I, Ahmadi M, Tounsi M, Rumpel C, Mammou AB, Le Bissonnais Y. 2013. Fingerprinting sediment sources in the outlet reservoir of a hilly cultivated catchment in Tunisia. Journal of Soil and Sediments 13: 801-815. DOI. 10.1007/s11368-012-0642-6

Small IF, Rowan JS, Franks SW. 2002. Quantitative sediment fingerprinting using a Bayesian uncertainty estimation framework. In The Structure, Function and Management Implications of Fluvial Sedimentary Systems, Dyer FJ, Thomas MC, Olley JM (eds), IAHS Publication 276. IAHS Press: Wallingford; 443-450.

Smith HG, Blake WH. 2014. Sediment fingerprinting in agricultural catchments: a critical re-examination of source discrimination and data corrections. Geomorphology 204: 177-191. DOI. 10.1016/j. geomorph.2013.08.003

Smith HG, Blake WH, Owens PN. 2013. Discriminating fine sediment sources and the application of sediment tracers in burned catchments: a review. Hydrological Processes 27: 943-958. DOI. 10.1002/hyp.9537 
Smith VH, Tilman GD, Nekola JC. 1999. Eutrophication: impacts of excess nutrient inputs on freshwater, marine, and terrestrial ecosystems Environmental Pollution 100: 179-196. DOI. 10.1016/S0269-7491 (99)00091-3

Theuring P, Rode M, Behrens S, Kirchner G, Jha A. 2013. Identification of fluvial sediment sources in the Kharaa River catchment, Northern Mongolia. Hydrological Processes 27: 845-856. DOI. 10.1002/ hyp.9684

Thompson JJD, Doody DG, Flynn R, Watson CJ. 2012. Dynamics of critical source areas: does connectivity explain chemistry? Science of the Total Environment 435-436: 499-508. DOI. 10.1016/j. scitotenv.2012.06.104

Thompson J, Cassidy R, Doody DG, Flynn R. 2013. Predicting critical source areas of sediment in headwater catchments. Agriculture, ECOsystems and Environment 179: 41-52. DOI. 10.1016/j. agee.2013.07.010

Tremblay L, Alaoui G, Léger MN. 2011. Characterization of aquatic particles by direct FT-IR analysis of filter and quantification of elemental and molecular compositions. Environment, Science, and Technology 45: 9671-9679. DOI. 10.1021/ac011043g

Walling DE. 2013. The evolution of sediment source fingerprinting investigations in fluvial systems. Journal of Soils and Sediments 13: 1658-1675. DOI. 10.1007/s11368-013-0767-2

Walling DE, Collins AL, Stroud RW. 2008. Tracing suspended sediment and particulate phosphorus sources in catchments. Journal of Hydrology 350: 274-289. DOI. 10.1016/j.jhydrol.2007.10.047

Wensum Alliance. 2014. River Wensum Demonstration Test Catchment Project. http://www.wensumalliance.org.uk

Wilkinson SN, Hancock GJ, Bartley R, Hawdon AA, Keen RJ. 2013. Using sediment tracing to assess processes and spatial patterns of erosion in grazed rangelands, Burdekin River basin, Australia. Agriculture, Ecosystems and Environment 180: 90-102. DOI. 10.1016/j. agee.2012.02.002

Williams GP. 1989. Sediment concentration versus water discharge during single hydrologic events in rivers. Journal of Hydrology 111: 89-106. DOI. 10.1016/0022-1694(89)90254-0 